Xu, Y., B. Wang, L. Dou, H. Yue, N. Yang, L. Yang, S. Liu, and J. Ran. 2016. Estimating density of a rare and cryptic high-mountain Galliform species, the Buff-throated Partridge Tetraophasis szechenyii. Avian Conservation and Ecology 11(1):10. http://dx.doi.org/10.5751/ ACE-00853-110110

Copyright (C) 2016 by the author(s). Published here under license by the Resilience Alliance.

Short Communication

\title{
Estimating density of a rare and cryptic high-mountain Galliform species, the Buff-throated Partridge Tetraophasis szechenyii
}

Yu Xu ${ }^{1,2,3}$, Bin Wang $^{3}$, Liang Dou ${ }^{3}$, Hanqiu Yue ${ }^{1}$, Nan Yang ${ }^{3}$, Liu Yang ${ }^{1}$, Shirong Liu ${ }^{2}$ and Jianghong Ran ${ }^{3}$

${ }^{1}$ School of Resources and Environmental Sciences, Pingdingshan University, ${ }^{2}$ Institute of Forest Ecology, Environment and Protection, Chinese Academy of Forestry, ${ }^{3}$ School of Life Sciences, Sichuan University

\begin{abstract}
Estimates of abundance or density are essential for wildlife management and conservation. There are few effective density estimates for the Buff-throated Partridge Tetraophasis szechenyii, a rare and elusive high-mountain Galliform species endemic to western China. In this study, we used the temporary emigration N-mixture model to estimate density of this species, with data acquired from playback point count surveys around a sacred area based on indigenous Tibetan culture of protection of wildlife, in Yajiang County, Sichuan, China, during April-June 2009. Within 84 125-m radius points, we recorded 53 partridge groups during three repeats. The best model indicated that detection probability was described by covariates of vegetation cover type, week of visit, time of day, and weather with weak effects, and a partridge group was present during a sampling period with a constant probability. The abundance component was accounted for by vegetation association. Abundance was substantially higher in rhododendron shrubs, fir-larch forests, mixed spruce-larch-birch forests, and especially oak thickets than in pine forests. The model predicted a density of 5.14 groups $/ \mathrm{km}^{2}$, which is similar to an estimate of $4.7-5.3$ groups $/ \mathrm{km}^{2}$ quantified via an intensive spot-mapping effort. The post-hoc estimate of individual density was 14.44 individuals $/ \mathrm{km}^{2}$, based on the estimated mean group size of 2.81 . We suggest that the method we employed is applicable to estimate densities of Buff-throated Partridges in large areas. Given importance of a mosaic habitat for this species, local logging should be regulated. Despite no effect of the conservation area (sacred) on the abundance of Buff-throated Partridges, we suggest regulations linking the sacred mountain conservation area with the official conservation system because of strong local participation facilitated by sacred mountains in land conservation.
\end{abstract}

\section{Estimation de la densité d'une espèce de Galliformes de haute altitude rare et cryptique, le Tétraophase de Szecheny Tetraophasis szechenyii}

RÉSUMÉ. Les estimations de l'abondance ou de la densité sont essentielles pour la gestion et la conservation de la faune. Il existe peu d'estimations valides de la densité du Tétraophase de Szecheny Tetraophasis szechenyii, une espèce de Galliformes de haute altitude rare et furtive, endémique de l'ouest de la Chine. Dans la présente étude, nous avons utilisé le modèle N-mélange avec émigration temporaire pour estimer la densité de cette espèce, à partir de dénombrements par points d'écoute avec enregistrements sonores, aux alentours d'un endroit sacré selon la culture tibétaine indigène de protection de la faune, dans le comté de Yajiang, Sichuan, en Chine, d'avril à juin 2009. À 84 points d'écoute de $125 \mathrm{~m}$ de rayon, nous avons enregistré 53 groupes de tétraophase durant trois répétitions. Le meilleur modèle a révélé que la probabilité de détection était faiblement associée aux covariables type de couvert végétal, semaine de visite, heure du jour et aux conditions météorologiques, et la probabilité qu'un groupe de tétraophase soit présent durant une période échantillonnée était constante. L'abondance s'expliquait par l'assemblage végétal et était substantiellement plus élevée dans les buissons de rhododendron, les forêts de sapins et de mélèzes, les forêts mixtes d'épinettes, de mélèzes et de bouleaux, et tout particulièrement dans les fourrés de chênes, en comparaison aux forêts de pins. Le modèle a prédit une densité de 5,14 groupes $/ \mathrm{km}^{2}$, résultat comparable à une estimation de 4,7 à 5,3 groupes $/ \mathrm{km}^{2}$ obtenue grâce à un effort intense de cartographie des territoires. L'estimation post-hoc de la densité des individus était de 14,44 individus $/ \mathrm{km}^{2}$, fondée sur la taille moyenne des groupes estimée à 2,81 . Selon nous, la méthode que nous avons employée est applicable pour estimer les densités de Tétraophase de Szecheny sur de grandes étendues. Étant donné l'importance de la mosaïque de milieux pour cette espèce, la récolte locale de bois devrait être réglementée. Malgré l'absence d'effet de la zone de conservation (sacrée) sur l'abondance des Tétraophases de Szecheny, nous proposons d'instaurer des règlements afin d'intégrer l'aire de conservation de la montagne sacrée au système de conservation officiel, en raison de la forte participation locale à la conservation des terres en présence de montagnes sacrées.

Key Words: conservation; density estimate; Galliformes; playback; point counts; sacred area; territorial

Address of Correspondent: Shirong Liu, Institute of Forest Ecology, Environment and Protection, Chinese Academy of Forestry, Dongxiaofu No.1, Haidian District, Beijing 100091, PR. China, liusr@caf.ac.cn 


\section{INTRODUCTION}

Estimates of abundance or density are fundamental to wildlife management and conservation (Bibby et al. 1998). Yet imperfect detection and zero inflation in count data can introduce estimation error and obscure ecological patterns (Dénes et al. 2015). Although total counts may not be possible on sample plots of a larger area of interest, particularly for rare or elusive species in dense habitats, statistical advances such as N-mixture models (Dénes et al. 2015) permit to account for these issues in estimates.

The Buff-throated Partridge Tetraophasis szechenyii is a rare and elusive Galliform species endemic to western China, distributed in high mountains of southeastern Tibet, southern Qinghai, western Sichuan, and northwestern Yunnan (MacKinnon and Phillipps 2000, Madge and McGowan 2002). This species breeds primarily between April and June, and is territorial during the breeding season, living in monogamous pairs, or in cooperative groups comprising a breeding pair, and up to three helpers of either sex (Xu et al. 2011). It is considered to be endangered based on the Red Book of China and is legally listed in Category I of the nationally protected animals (Wang and Xie 2004). It was estimated to have a population of approximately 25,000-40,000 individuals over 3000 $\mathrm{km}^{2}$ in eastern Tibet (Liu and Ci 1993), and the small population is likely to be declining owing to ongoing habitat degradation and hunting across its range ( $\mathrm{Lu} \mathrm{2006).}$

This species was surveyed through line-transect or plot methods based on direct visual and/or auditory detections in several sites (Table 1, see Fig. 1A for locations of surveys). These surveys generated indices of abundance rather than estimates of absolute density because of imperfect detection, despite repeated surveys. Based on spot-mapping in a four-year behavioral study that determined the location of all partridge groups from repeated searches aided by playback and radio-tracking within $3.4 \mathrm{~km}^{2}$ study area (Xu et al. 2011), a density of $4.7-5.3$ groups $/ \mathrm{km}^{2}$ and a mean group size of $2.81(2.63-2.99,95 \% \mathrm{CI}, \mathrm{n}=68)$ were calculated. Despite a high level of accuracy in the measure of bird numbers (Buckland 2006), this approach is not practical for surveying large areas, which are often required in population monitoring. In addition, problems may arise when trying to distinguish individual birds (Stewart-Cox and Quinnell 1990).

We conducted point counts to survey Buff-throated Partridges in a larger area, and used the temporary emigration $\mathrm{N}$-mixture model to estimate density. In the model, we examined multiple hypotheses related to local abundance, the probability of being present, i.e., availability, and the detection probability inferred by the model (Chandler et al. 2011). In particular, we expected differences in abundance among habitat types, with oak thickets having substantially higher Buff-throated Partridges abundance compared with pine forests, based on the breeding season habitat-use pattern documented by $\mathrm{Xu}$ et al. (2016). Given the linkage between abundance and traditional Buddhist Tibetan culture (e.g., Shen et al. 2012, Brandt et al. 2013), and more protection and supplemental feeding provided to Buff-throated Partridges in the sacred patch within a monastery (Yang et al. 2011, 2016), we predicted higher abundance of Buff-throated Partridges in the sacred area than in the nonsacred area.
Fig. 1. Map showing (A) locations of published studies for estimating index of Buff-throated Partridge (Tetraophasis szechenyii) abundance, and (B) our study area (Pamuling) in Yajiang County, Garzê Tibetan Autonomous Prefecture, Sichuan, western China.
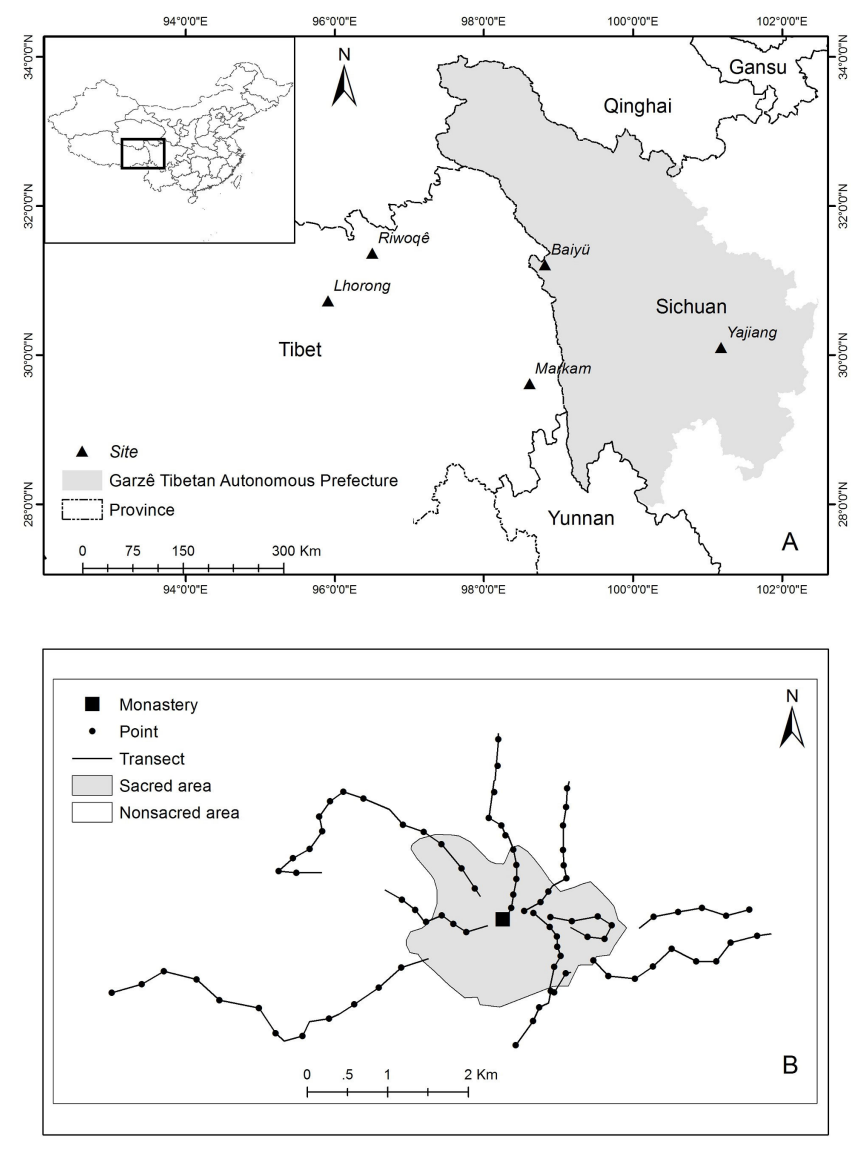

\section{METHODS}

\section{Study site}

We conducted the study in Pamuling $\left(30^{\circ} 06^{\prime} \mathrm{N} 101^{\circ} 11^{\prime} \mathrm{E}\right.$; Fig. 1$)$, Yajiang County, Garzê Tibetan Autonomous Prefecture, Sichuan, China. The area of the study site was approximately 50 $\mathrm{km}^{2}$ with elevation ranging from $3300 \mathrm{~m}$ to $4300 \mathrm{~m}$. A Tibetan monastery, located in the center of the site, and its associated sacred mountain covers $3.4 \mathrm{~km}^{2}$ at an elevation of 3900 to 4200 $\mathrm{m}$. The monks and local people that visited the sacred mountain had provided supplemental feeding for wildlife, especially Buffthroated Partridges within the sacred area, because of the Buddhist perspective that values all living beings. During 2006 2009, Xu et al. (2011) conducted a behavioral-ecology study of Buff-throated Partridges within the sacred area.

The subhumid climate of the Qinghai-Xizang Plateau predominates, with the breeding season of Buff-throated Partridges occurring mainly from April to June. The habitat is 
Table 1. Summary of published studies for estimating index of Buff-throated Partridge (Tetraophasis szechenyii) abundance.

\begin{tabular}{|c|c|c|c|c|c|c|}
\hline Site & Month & Method & Sampling area & Repeat & $\begin{array}{l}\text { Index of abundance } \\
\text { (individuals } / \mathrm{km}^{2} \text { ) }\end{array}$ & Reference \\
\hline $\begin{array}{l}\text { Riwoqê County, } \\
\text { Tibet }\end{array}$ & August & Plot & Three approximately $0.1-\mathrm{km}^{2}$ plots & $5-6$ & 36.7 & Liu and $\mathrm{Ci}(1993)$ \\
\hline $\begin{array}{l}\text { Lhorong County, } \\
\text { Tibet }\end{array}$ & August & Plot & Four approximately $0.1-\mathrm{km}^{2}$ plots & $4-6$ & 37.8 & Liu and $\mathrm{Ci}(1993)$ \\
\hline $\begin{array}{l}\text { Lhorong County, } \\
\text { Tibet }\end{array}$ & August & Plot & Two approximately $0.1-\mathrm{km}^{2}$ plots & 6 & 72.5 & Liu and $\mathrm{Ci}(1993)$ \\
\hline $\begin{array}{l}\text { Baiyü County, } \\
\text { Sichuan }\end{array}$ & April - May & Plot & Three $1.5-6.25-\mathrm{km}^{2}$ plots & 11 & $2.4-3$ & Wu et al. (1994) \\
\hline $\begin{array}{l}\text { Garze Tibetan } \\
\text { Autonomous } \\
\text { Prefecture Sichun }\end{array}$ & - & Line-transect & - & $>5$ & 1.2 & Peng (1996) \\
\hline $\begin{array}{l}\text { Yajiang County, } \\
\text { Sichuan }\end{array}$ & March & Plot & Three $0.2-\mathrm{km}^{2}$ plots & 10 & $3-11$ & Wen et al. (2008) \\
\hline
\end{tabular}

classified as forest, thicket, and shrub based on cover type. In detail, it consists mainly of five vegetation associations: (1) firlarch forests (FF), dominated by Abies squamata, and Larix potaninii; (2) mixed spruce-larch-birch forests (DBCF), dominated by Picea sp., L. potaninii, and Betula platyphylla; (3) oak thickets (OT), dominated exclusively by Quercus aquifolioides; (4) pine forests (PPF), dominated exclusively by Pinus densata; (5) rhododendron shrubs (RS), dominated by Rhododendron nitidulum, Rh. flavoflorum, Salix sp., and Dasiphora fruticosa. Pine forests are characterized by sparse grasses with heavy leaf-litters, compared with the other four habitat associations (Xu et al. 2016).

\section{Field survey}

The field survey was conducted during the breeding season of the Buff-throated Partridge, from April to June 2009. Point counts, a method where observers record birds seen or heard from stationary points positioned along a transect route, was used to survey Buff-throated Partridges. The elusive behavior of this species made it difficult to detect by visual cues except for those living in the small sacred area. We therefore used vocal cues for monitoring. Partridge groups generally called during the daytime to advertise their territories, and every group member might vocalize, with loud sounds that can travel more than $200 \mathrm{~m}$. However, singing activity can be low, so we introduced playback into the survey to stimulate responses and increase detection rates. The recording was one 40-s territorial chorus (see Fig. 2 for spectrogram) selected from a library of recordings from a JWD Recorder with a built-in MP3 Player (model DVR-892, Shenzhen, China). This chorus worked well in stimulating vocal responses from Buff-throated Partridges in previous research (e.g., Xu et al. 2011, Yang et al. 2011), if it was performed within their territories.

Ten transects of $0.3-5 \mathrm{~km}$ were set across the site (Fig. 1B), with each transect usually covering two or three vegetation associations. Eighty-four point stations were established (29 in the sacred patch and 55 outside; 27 in oak thickets, 13 in mixed spruce-larch-birch forests, 16 in fir-larch forests, 8 in rhododendron shrubs, and 20 in pine forests). Following the suggestion from Bibby et al. (1998) on the spacing of stations in dense forests, we positioned stations approximately every $250 \mathrm{~m}$ along a transect route, where we limited a detection radius of 125 $\mathrm{m}$. To quantify or characterize vegetation associations, we required all the stations be at least $125 \mathrm{~m}$ from a vegetation edge. The limitation of $125 \mathrm{~m}$ effective radius was to reduce double call counts. This limitation also contributed to reduce distance-related heterogeneity that will generally violate $\mathrm{N}$-mixture models (Nichols et al. 2009, Kery and Royle 2015), because only partridges that had naturally high detection probabilities were included.

Fig. 2. (A) Spectrograms of the territorial chorus of the Buffthroated Partridges used in the study (settings: Hann type, window size $=512$ samples, Discrete Fourier Transformation length $=1024$ samples, and overlap $=97.1 \%$, with a time resolution of $0.34 \mathrm{~ms}$ and a frequency resolution of $43.1 \mathrm{~Hz}$, respectively); (B) An typical syllable of prelude phase; (C) An typical syllable of loud song phase. Spectrograms were made with Raven Pro 1.4 (Charif et al. 2010).

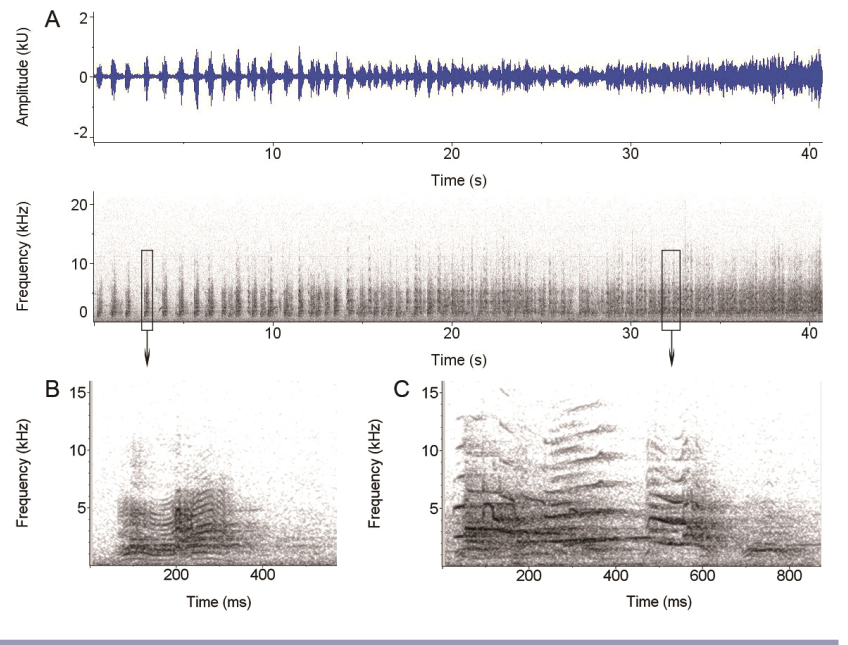

The survey was scheduled every month, between $0730-1740$, at least 40 minutes after sunrise and 120 minutes before sunset, on days without rain or snow (when Buff-throated Partridges were active and were responsive to the playback). A team of two 
persons, who had practiced estimating distances, walked along transects. At each station, we played the 40-s territorial chorus, using the JWD Recorder with MP3 player at a height of approximately $2 \mathrm{~m}$ where the speaker volume was set to match the intensity typical of Buff-throated Partridge territorial calls. As soon as a group responded, the playback was stopped; otherwise, the playback was repeated once after a 2-min interval. False negatives might occur because we stopped the playback, but there would be few, in the sense that territorial calls from the responding groups should have the same effects as the broadcast on stimulating other responses.

The observers remained at each station for 10 minutes, recording the number of vocal responses within $125 \mathrm{~m}$ of the point station. Pairs or groups were the fundamental unit of observation. We recorded one response if more than one bird vocalized in similar places within the allotted time, because they were very likely to be from the same pair or group. If responses originated from different positions within the allotted time, we counted them as different pairs or groups. We used a GPS (model Garmin eTrex Venture, Taipei, Taiwan) and a clinometer (accuracy: $30^{\prime} \pm 5^{\prime} / 2$ mm for azimuth measurement, and $20^{\prime} \pm 5^{\prime} / 2 \mathrm{~mm}$ for inclination measurement; model DQY-1, Harbin, China) to measure the topographical features of each point, including altitude, slope, and aspect (which was recorded as warm or cold slope, corresponding to $45-224^{\circ}$, or $0-44^{\circ}$, and $225-360^{\circ}$, respectively; Shen et al. 2012). At each point station, we also recorded weather conditions (sunny/cloudy).

\section{Data analysis}

We used the temporary emigration $\mathrm{N}$-mixture model (Chandler et al. 2011), a variation of the basic N-mixture model (Royle 2004), to estimate density. The basic N-mixture model generates parameter estimates of the abundance distribution across sites (e.g., $\lambda$ in the case of a Poisson distribution) and detection probability ( $p$ ) by accounting for detection error and the resulting false zeros, but its assumption of closure, i.e., no migration or emigration during the survey period, is frequently violated when birds enter and leave sample plots during the course of sampling (Chandler et al. 2011). For example, it is quite possible that movement of birds occurs between repeated visits, if mobile birds have a home range that overlaps sampling plots (Nichols et al. 2009). The temporary emigration N-mixture model can explicitly account for temporary emigration by adding a binomial zero-inflation level and considering birds to be within the sampling plot with probability $\phi$, i.e., availability (Chandler et al. 2011).

The model is thus described as a three-level hierarchical model (Chandler et al. 2011):

$$
\begin{gathered}
M_{i} \sim \text { Poisson }(\lambda) \\
\text { for } i=1,2, \ldots, \text { R sample plots }
\end{gathered}
$$

Where $M_{i}$ is the number of birds that could potentially use each plot, i.e., the superpopulation size, an outcome of a discrete probability distribution of the Poisson with mean $\lambda$ used.

$$
N_{i j} \sim \operatorname{Binomial}\left(M_{i}, \phi\right)
$$

for $i=1,2, \ldots, \mathrm{R}$ sample plots;
Where $N_{i j}$ is the subset of the superpopulation present within a plot on a particular occasion. The number of birds available for detection at occasion $\mathrm{j}$ is a modeled as binomial with probability $\phi$.

$$
\begin{gathered}
y_{i j} \sim \text { Multinomial }\left(N_{i j}, \pi_{i j}\right) \\
\text { for } i=1,2, \ldots, \text { R sample plots; } \\
\quad j=1,2, \ldots, \text { T occasions }
\end{gathered}
$$

Where $y_{i j}$ is a vector of counts made at plot $\mathrm{i}$ on occasion $\mathrm{j}$ that arises conditional on $N_{i j}$ and the probability of detection (p). $\pi_{i j}$ is the multinomial cell probability computed from a function of the detection probability $\mathrm{p}$.

$\lambda$ is modeled using the log link, and $\varphi$ and $p$ are modeled as using the logit link. Density can be estimated by

$$
\widehat{D}=\frac{\widehat{E\left[N_{i j}\right]}}{A}=\frac{\hat{\lambda} \hat{\phi}}{A}
$$

Where $A$ is the plot area.

In the analysis, we included covariates at three levels: site, site-byyear, and observation. Based on biological explanations or hypotheses (Bibby et al. 1998, Dénes et al. 2015), we considered vegetation association and topography, including altitude, slope, and aspect, as covariates for the abundance component of the model. For detection probability, we considered vegetation cover type, week of visit, time of day (standardized as minutes past sunrise; exact data on sunrise times were downloaded from the website http://www.time.ac.cn/serve/sunriseset/test.asp), and weather. Additionally, we considered sacred patch and nonsacred patch as covariates. Given more protection for wildlife by the Tibetan monastery (e.g., Shen et al. 2012, Brandt et al. 2013), and tameness of partridges associated with traditional protection practices (Xu et al. 2011), differences in abundance and detection probability of partridges might also occur between the sacred and nonsacred patches. For availability, we included week of visit, which may affect availability of partridges by influencing their movement (Lehmicke 2014).

We ranked models based on the Akaike information criterion (AIC). We did the following model selection in the hierarchical model. The first step was to fit the three submodels described above separately while keeping other components constant. We constructed models from the individual covariates and combinations of these covariates based on biological explanations, and 18, 1 , and 5 candidate models were constructed for detection, availability, and abundance, respectively, as well as the null model, i.e., intercept only. We then took the top detection model and reran it with any other availability and/or abundance models within 2 AIC from the top model in its respective set that have equivalent support to explain the data (Burnham and Anderson 2002). We identified the final best model when $\triangle \mathrm{AIC}$ between it and the next best model was $>2$, or we adopted a multimodel inference approach using averaged parameter estimates from the range of models with $\triangle \mathrm{AIC} \leq 2$ (Burnham and Anderson 2002). We assessed model fit using the parametric bootstrapping function (parboot). One thousand bootstraps were run, and the Freeman-Tukey test was used to assess fit. We calculated $95 \%$ confidence interval $(95 \% \mathrm{CI})$ for parameter estimates, and 
considered variables statistically important when their 95\% CIs did not overlap 0 . We used the "predict" function to estimate density based on the best model and made model predictions along the range of covariate values. We estimated $95 \%$ CIs around the estimates of densities using the "parboot" function with 1000 bootstraps. The analysis was performed in program R 3.2.0 ( R Development Core Team 2015), with the "gpcount" function in package unmarked (Fiske et al. 2015).

It should be noted that because pairs or groups were the fundamental unit of observation in this study, equation (4) gives estimated density of groups. To get an estimate of individual density (Buckland et al. 2008), we multiplied this by the estimate of mean group size, $2.81(2.63-2.99,95 \% \mathrm{CI})$, based on spotmapping in a four-year behavioral study within $3.4 \mathrm{~km}^{2}$ study area (Xu et al. 2011).

\section{RESULTS}

We detected 53 partridge groups within all point visits; the number of detections decreased as the season progressed (Table 2). On average, $0.21(0.15-0.27,95 \% \mathrm{CI})$ groups were detected per point, and the direct estimate was $4.28(3.00-5.56,95 \% \mathrm{CI})$ groups $/ \mathrm{km}^{2}$.

Table 2. Monthly number of Buff-throated Partridge (Tetraophasis szechenyii) groups detected within 84 125-m radius points.

\begin{tabular}{lcc}
\hline \hline Month & $\begin{array}{c}\text { Total } \\
\text { number }\end{array}$ & Mean number per point $(95 \% \mathrm{CI})$ \\
\hline April & 20 & $0.24(0.13-0.35)$ \\
May & 18 & $0.21(0.11-0.32)$ \\
June & 15 & $0.18(0.09-0.27)$ \\
\hline
\end{tabular}

Our model selection results are shown in Table 3. The best detection model included vegetation cover type, week of visit, time of day, and weather, with no other models within $2 \Delta \mathrm{AIC}$ of the best one. For availability, the top model was the null, with week of visit falling within 2 AIC units. However, when we reran our best detection model with week of visit as the availability model, it was not within 2 AIC of the best detection model with a null availability model. The top abundance model included vegetation association only, with no other models within 2 AIC of it. Parametric bootstrapping simulations and the FreemanTukey test indicated that the final best model provided a reasonable fit to the dataset $(P=0.788)$. The final model indicated weak effects of vegetation cover type, week of visit, time of day, and weather on detection probability because they had a $95 \%$ CI in parameter estimates broadly overlapping 0 (Table 4). Each member of the superpopulation was present at the survey plots with a constant probability of 0.08 during the sampling period (Table 4). Abundance was substantially higher in rhododendron shrubs, fir-larch forests, mixed spruce-larch-birch forests, and especially oak thickets than in pine forests, as indicated by $95 \%$ CI for parameter estimates that either did not overlap 0 or narrowly overlapped 0 (Table 4 ), while there were no statistical significances between the first four vegetation associations.

The predicted group density was 5.14 (3.9-6.8, 95\% CI) groups/ $\mathrm{km}^{2}$ based on the best model (the predicted habitat-specific group densities are shown in Fig. 3). The post-hoc estimate of individual density was $14.44(10.84-19.20,95 \% \mathrm{CI})$ individuals $/ \mathrm{km}^{2}$, based on the estimated mean group size of $2.81(2.63-2.99,95 \% \mathrm{CI}$; $\mathrm{Xu}$ et al. 2011).

Fig. 3. Habitat-specific Buff-throated Partridge (Tetraophasis szechenyii) density estimates and $95 \%$ confidence intervals. Abbreviation: RS, rhododendron shrubs; OT, oak thickets; FF, fir-larch forests; DBCF, spruce-larch-birch mixed forests; PPF, pine forests.

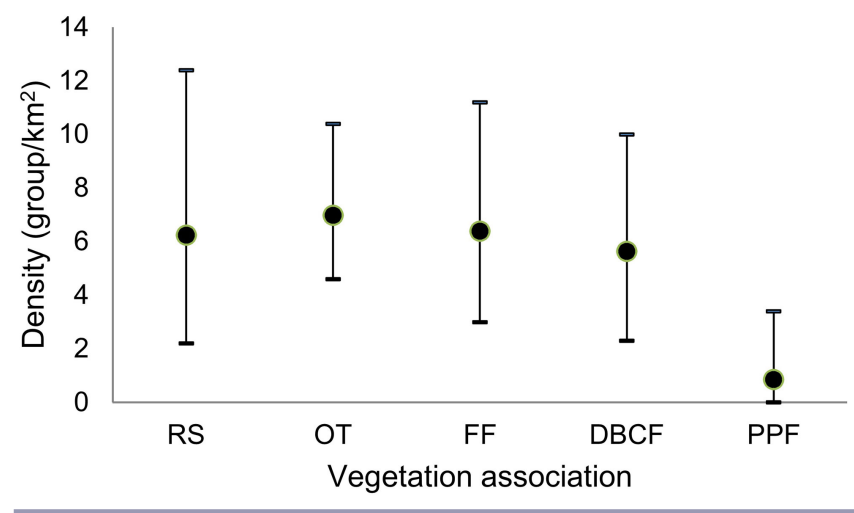

\section{DISCUSSION}

We used the playback point count technique to survey elusive, but territorial Buff-throated Partridges. The temporary emigration $\mathrm{N}$-mixture model we employed addressed the probability that a group was present, when partridges were likely to enter and leave sample plots during the course of sampling. Although we did not quantify how much the playback improved detections, the model estimated and adjusted detection probabilities by covariates of vegetation cover type, week of visit, time of day, and weather, which then provided the basis for detection-corrected estimates of abundance and density. The density estimate from the statistical model was 5.14 groups $/ \mathrm{km}^{2}$, a $20.1 \%$ increase compared with the direct estimate without adjusting detection error.

The number of detections declined throughout the season, but we do not interpret decline in actual abundance or density because of permanent emigration, or influence such as predation or illness on survival that may violate assumptions required by the model (Dail and Madsen 2011). During the course of the previous research (e.g., Xu et al. 2011), we found that emigrations from the study area were infrequent and the mortality rate was quite low throughout the breeding season. We speculate that decline in the number of detections is probably due to reduced intensity of territorial behavior and partridges becoming less responsive to playback as the season progressed. However, use of playback may raise concerns because of violations of some assumptions when adopting N-mixture models (Kery and Royle 2015). For example, movement of birds might be elicited by playback prior to vocalization and detection (Franco et al. 2006, Fuller et al. 2012); detections of groups might not be independent because responses to playback by one group will make it more likely that individuals in neighboring groups vocalize (Franco et al. 2006). In addition, group size may affect detection probability positively (Royle 2008). Although the model indicated that bird abundance was likely underestimated if detection probability was not accounted for, the model estimating detection probabilities was quite 
Table 3. Number of parameters (nPars), Akaike information criterion (AIC), $\Delta \mathrm{AIC}$, and Akaike weights ( $\mathrm{w}_{\mathrm{i}}$ ) for the 95\% confidence set of candidate models of Buff-throated Partridge (Tetraophasis szechenyii) abundance $(\lambda)$, availability $(\varphi)$, and detection probability $(\mathrm{p})$.

\begin{tabular}{|c|c|c|c|c|}
\hline Model & nPars & $\mathrm{AIC}$ & $\Delta \mathrm{AIC}$ & $\mathrm{w}_{\mathrm{i}}$ \\
\hline \multicolumn{5}{|l|}{$\mathrm{p}$} \\
\hline Vegetation cover type $^{\dagger}+$ Week + Time + Weather ${ }^{\ddagger}$ & 8 & 267.30 & 0 & 0.79 \\
\hline Vegetation cover type $^{\dagger}+$ Weather ${ }^{\ddagger}+$ Patch $^{\S}$ & 7 & 271.17 & 3.87 & 0.11 \\
\hline Vegetation cover type $^{\dagger}+$ Week + Time + Weather ${ }^{\ddagger}+$ Patch $^{\S}$ & 9 & 272.66 & 5.36 & 0.05 \\
\hline \multicolumn{5}{|l|}{$\varphi$} \\
\hline Null & 3 & 285.03 & 0 & 0.65 \\
\hline Week & 4 & 286.23 & 1.20 & 0.35 \\
\hline \multicolumn{5}{|l|}{$\lambda$} \\
\hline Vegetation association' & 7 & 272.36 & 0 & 0.57 \\
\hline Vegetation association + Altitude + Aspect $^{\mathbb{I}}+$ Slope + Patch $^{\S}$ & 11 & 274.48 & 2.13 & 0.20 \\
\hline Vegetation association + Altitude + Aspect ${ }^{\mathbb{T l}}+$ Slope & 10 & 274.78 & 2.42 & 0.17 \\
\hline \multicolumn{5}{|c|}{$\begin{array}{l}{ }^{7} \text { Forest and thicket compared with shrub. } \\
{ }^{\$} \text { Sunny compared with cloudy. } \\
\text { I Sacred compared with nonsacred patch. } \\
\text { ' Rhododendron shrubs (RS), oak thickets (OT), fir-larch forests (FF), and spruce-larch-birch mixed forests } \\
\text { (DBCF) compared with pine forests (PPF). } \\
\text { "I Warm compared with cold slope. }\end{array}$} \\
\hline
\end{tabular}

Table 4. Best model (AIC $=264.30)$ parameter estimates, standard errors $(\mathrm{SE})$, and $95 \%$ confidence intervals (CI) used to explain Buff-throated Partridge (Tetraophasis szechenyii) abundance $(\lambda)$, availability $(\varphi)$, and detection probability (p). Estimates are on the $\log$-scale for $\lambda$ and on the $\operatorname{logit}$-scale for $\varphi$ and $p$.

\begin{tabular}{|c|c|c|c|c|}
\hline Submodel & Estimate & SE & \multicolumn{2}{|c|}{$95 \% \mathrm{CI}$} \\
\hline \multicolumn{5}{|l|}{$\lambda$} \\
\hline Intercept & -0.62 & 1.60 & -3.76 & 2.51 \\
\hline Vegetation association ${ }^{\dagger}$ (RS vs PPF) & 1.98 & 1.09 & -0.16 & 4.12 \\
\hline Vegetation association $^{\dagger}$ (OT vs PPF) & 2.09 & 1.02 & 0.09 & 4.09 \\
\hline Vegetation association $^{\dagger}$ (FF vs PPF) & 2.01 & 1.05 & -0.05 & 4.06 \\
\hline Vegetation association $^{\dagger}$ (DBCF vs PPF) & 1.88 & 1.06 & -0.20 & 3.96 \\
\hline \multicolumn{5}{|l|}{$\varphi$} \\
\hline Intercept & -2.46 & 1.38 & -5.16 & 0.24 \\
\hline \multicolumn{5}{|l|}{$\mathrm{p}$} \\
\hline Intercept & 119.70 & 143.40 & -161.36 & 400.76 \\
\hline Vegetation cover type (Forest vs Shrub) $^{\ddagger}$ & -8.20 & 31.50 & -69.94 & 53.54 \\
\hline Vegetation cover type $^{\ddagger}$ (Thicket vs Shrub) & -245.40 & 287.30 & -808.51 & 317.71 \\
\hline Week & 75.40 & 85.90 & -92.96 & 243.76 \\
\hline Time & -97.10 & 111.80 & -316.23 & 122.03 \\
\hline Weather ${ }^{\S}$ & 354.60 & 410.60 & -450.18 & 1159.38 \\
\hline \multicolumn{5}{|c|}{$\begin{array}{l}{ }^{\dagger} \text { Rhododendron shrubs (RS), oak thickets (OT), fir-larch forests (FF), and spruce-larch-birch mixed forests } \\
\text { (DBCF) compared with pine forests (PPF). } \\
{ }^{\ddagger} \text { Forest and thicket compared with shrub. } \\
{ }^{\S} \text { Sunny compared with cloudy. }\end{array}$} \\
\hline
\end{tabular}


uncertain (see Table 4). The high variability of the model estimates for detection probability might tend to yield bias in abundance estimates. Despite these possible effects, the density estimate by the statistical model is similar to an estimate, $4.7-5.3$ groups/ $\mathrm{km}^{2}$, obtained by intensive spot-mapping efforts from a small area $\left(3.4 \mathrm{~km}^{2}\right)$ in the site during $2006-2008$. Therefore, the model is statistically robust. Because the method had higher precision in the density estimate, we suggest that it is practical to implement for estimating densities of Buff-throated Partridges in large areas. With the predicted density of groups, one can multiply this by the average number of individuals per group in the population to get a post-hoc estimate of individual density. Furthermore, it has potential to estimate the total population size of this species throughout its range, provided that there are density estimates in the different vegetation types at multiple sites and detailed land cover information is available.

Vegetation type accounted for the abundance component of the model. Buff-throated Partridge abundance was substantially higher in rhododendron shrubs, fir-larch forests, oak thickets, and mixed spruce-larch-birch forests than in pine forests. However, we did not detect any significant differences in abundance between the first four vegetation types although Buff-throated Partridges preferred oak thickets. Our results agree with Xu et al. (2016), but may better reflect reality because we surveyed birds during their foraging activities after they had dispersed from their roosting sites in fir-larch forests (Xu et al. 2010, 2014) and adjusted detection probabilities using models. Also, they nest mainly in firlarch forests, rhododendron shrubs, and oak thickets (Zhang et al. 2011).

It is thought that the traditional Buddhist Tibetan culture plays an essential role in contributing to abundance (Shen et al. 2012, Brandt et al. 2013). However, we did not find effects of the monastery and the supplemental feeding on partridge abundance. Because of the cultural or religious influence on protection of wildlife, species or individuals are relatively tame and easier to detect visually. For example, Buff-throated Partridges were often approached without disturbance to within $10 \mathrm{~m}$ in sacred patches (e.g., Xu et al. 2011). Easier detection might have resulted in an illusion of higher abundance in some studies. Our study avoided this problem because we surveyed Buff-throated Partridges auditorily by using playback to elicit vocalizations rather than visually. As evidence, the best model suggested that detection probability was not influenced by the sacred (Table 3 ).

Topography affects birds via influences on the local climate (Sutherland and Green 2004). Topographical features have been reported to be important predictors of the occurrence of individual species in many montane Galliformes especially during winter (Lu and Ciren 2002, Jia et al. 2005, Xu et al. 2006, Liao et al. 2007), as well as of selection of roosting sites in Buff-throated Partridges (Xu et al. 2010, 2014). In this study, however, we did not find an obvious relationship between Buff-throated Partridge abundance and topographical features. The Buff-throated Partridges might not have specifically thermal requirements while foraging during the relatively warm breeding season.

Given functional changes of habitat-use patterns by Buffthroated Partridges, managers should maintain a mosaic of habitats (Zhang et al. 2011, Xu et al. 2016), including oak thickets, mixed spruce-larch-birch forests, fir-larch forests, and rhododendron shrubs. Despite the commercial logging ban in 1998, the woodlands are under threat from cutting by the local communities. Q. aquifolioides is a good source for cooking and fire heating and oak thickets are most severely threatened by humans. Cutting for house-building purposes also occurs frequently in mixed spruce-larch-birch forests (Wang et al. 2012), which were not thought of as an important habitat for Buffthroated Partridges in the previous studies (e.g., Xu et al. 2010, 2014, Zhang et al. 2011) and have been ignored in conservation management. It has been suggested that cutting should be regulated by structuring locations and times (Xu et al. 2016), because of the difficulty in restricting the local people's access to the woodlands in Tibetan areas. This study indicates no effect of the sacred on abundance of Buff-throated Partridges, but we should recognize strong local participation in land conservation based on sacred mountains where cutting is generally prohibited by their traditional culture (Shen et al. 2012, Wang et al. 2012). Considering the huge amount and large land area of Tibetan sacred mountains (Shen et al. 2012), we suggest regulations be designed by linking the sacred mountain conservation area with the official conservation system. Besides, in light of the reduced cutting of woodlands in some villages that started to develop solar power, we suggest as a long-term management solution that villages develop energy sources other than wood fuel where possible.

Responses to this article can be read online at: http://www.ace-eco.org/issues/responses.php/853

\begin{abstract}
Acknowledgments:
We thank the Forestry Bureau of Yajiang County and Pamuling Monastery for permission and support for the fieldwork, and Pengfei $Y u$ for his assistance in data collection. We are grateful to Axios Review for helpful feedback on an early draft of this paper. This work was supported by the National Natural Science Foundation of China (Grant No. 31301896; 31172105), China Postdoctoral Science Foundation (Grant No. 2014M550885), and the Scientific Research Foundation for High-level Talents of Pingdingshan University (Grant No. 2012006).
\end{abstract}

\section{LITERATURE CITED}

Bibby, C., S. Marsden, and A. Fielding. 1998. Bird-habitat studies. Pages 99-114 in C. Bibby, M. Jones, and S. Marsden, editors. Expedition field techniques: bird surveys. Expedition Advisory Centre, Royal Geographical Society, London, UK.

Brandt, J. S., E. M. Wood, A. M. Pidgeon, L.-X. Han, Z. Fang, and V. C. Radeloff. 2013. Sacred forests are keystone structures for forest bird conservation in southwest China's Himalayan Mountains. Biological Conservation 166:34-42. http://dx.doi. org/10.1016/j.biocon.2013.06.014

Buckland, S. T. 2006. Point-transect surveys for songbirds: robust methodologies. Auk 123:345-357. http://dx.doi.org/10.1642/0004-8038 (2006)123[345:PSFSRM]2.0.CO;2 
Buckland, S. T., S. J. Marsden, and R. E. Green. 2008. Estimating bird abundance: making methods work. Bird Conservation International 18:S91-S108. http://dx.doi.org/10.1017/s0959270908000294

Burnham, K. P., and D. R. Anderson. 2002. Model selection and multimodel inference: a practical information-theoretic approach. Springer-Verlag, New York, New York, USA. http://dx.doi. org/10.1007/b97636

Chandler, R. B., J. A. Royle, and D. I. King. 2011. Inference about density and temporary emigration in unmarked populations. Ecology 92:1429-1435. http://dx.doi.org/10.1890/10-2433.1

Charif, R. A., A. M. Waack, and L. M. Strickman. 2010. Raven Pro 1.4 user's manual. Cornell Lab of Ornithology, Ithaca, New York, USA.

Dail, D., and L. Madsen. 2011. Models for estimating abundance from repeated counts of an open metapopulation. Biometrics 67:577-587. http://dx.doi.org/10.1111/j.1541-0420.2010.01465.x

Dénes, F. V., L. F. Silveira, and S. R. Beissinger. 2015. Estimating abundance of unmarked animal populations: accounting for imperfect detection and other sources of zero inflation. Methods in Ecology and Evolution 6:543-556. http://dx.doi. org/10.1111/2041-210x.12333

Fiske, I., R. Chandler, D. Miller, A. Royle, M. Kery, J. Hostetler, and R. Hutchinson. 2015. unmarked. R package version 0.11-0. R Foundation for Statistical Computing, Vienna, Austria. [online] URL: https://cran.r-project.org/web/packages/unmarked/.

Franco, P., K. Fierro-Calderón, and G. Kattan. 2006. Population densities and home range sizes of the Chestnut Wood-quail. Journal of Field Ornithology 77:85-90. http://dx.doi.org/10.1111/ j.1557-9263.2006.00026.x

Fuller, R. A., P. Akite, J. B. Amuno, C. L. Fuller, J. M. Ofwono, G. Proaktor, and R. Ssemmanda. 2012. Using playback of vocalisations to survey the Nahan's francolin, a threatened African forest galliform. Ostrich 83:1-6. http://dx.doi. org/10.2989/00306525.2012.677510

Jia, F., N. Wang, and G. M. Zheng. 2005. Winter habitat requirements of White Eared-pheasant Crossoptilon crossoptilon and Blood Pheasant Ithaginis cruentus in south-west China. Bird Conservation International 15:303-312. http://dx.doi.org/10.1017/ s095927090500047x

Kery, M., and J. A. Royle. 2015. Applied hierarchical modeling in ecology: analysis of distribution, abundance and species richness in $R$ and BUGS: Volume 1:Prelude and Static Models. Academic Press, Cambridge, Massachusetts, USA.

Lehmicke, A. J. J. 2014. Breeding ecology of the Seaside Sparrow (Ammodramus Maritimus) in Northern Gulf of Mexico Tidal Salt Marshes. Dissertation, University of Georgia, Athens, Georgia, USA.

Liao, W. B., C. Li, J. C. Hu, and X. Lu. 2007. Habitat utilization of the Sichuan Hill Partridge (Arborophila rufipectus) in the nonbreeding period in Laojunshan nature reserve. Zoological Research 28:172-178.

Liu, S. C., and R. Ci. 1993. Tetraophasis szechenyii of Tibet. Chinese Wildlife 15:19-21.
Lu, T. C. 2006. Buff-throated Partridge Tetraophasis szechenyii. Pages 54-60 in F. M. Lei, and T. C. Lu, editors. China endemic birds. Science Press, Beijing, China.

Lu, X., and S. Ciren. 2002. Habitat selection and flock size of Tibetan Partridge Perdix hodgsoniae during autumn-winter. Journal of the Yamashina Institute for Ornithology 33:168-175. http://dx.doi.org/10.3312/jyio1952.33.168

MacKinnon, J., and K. Phillipps. 2000. A field guide to the birds of China. Oxford University Press, Oxford, UK.

Madge, S., and P. McGowan. 2002. Pheasants, partridges and grouse: a guide to the pheasants, partridges, quails, grouse, guineafowl, buttonquails and sandgrouse of the world. Christopher Helm, London, UK.

Nichols, J. D., L. Thomas, and P. B. Conn. 2009. Inferences about landbird abundance from count data: recent advances and future directions. Pages 201-235 in D. L. Thomson, E. G. Cooch, and M. J. Conroy, editors. Modeling demographic processes in marked populations. Volume 3. Springer, New York, New York, USA. http://dx.doi.org/10.1007/978-0-387-78151-8_9

Peng, J. T. 1996. Pheasants in the Ganzi Autonomous Prefecture. Acta Zoologica Sinica 42(Suppl.):138-140.

R Development Core Team. 2015. R: a language and environment for statistical computing. R Foundation for Statistical Computing, Vienna, Austria.

Royle, J. A. 2004. N-mixture models for estimating population size from spatially replicated counts. Biometrics 60:108-115. http://dx.doi.org/10.1111/j.0006-341X.2004.00142.x

Royle, J. A. 2008. Hierarchical modeling of cluster size in wildlife surveys. Journal of Agricultural, Biological, and Environmental Statistics 13:23-36. http://dx.doi.org/10.1198/108571108x273188

Shen, X., S. Li, N. Chen, S. Li, W. J. McShea, and Z. Lu. 2012. Does science replace traditions? Correlates between traditional Tibetan culture and local bird diversity in Southwest China. Biological Conservation 145:160-170. http://dx.doi.org/10.1016/j. biocon.2011.10.027

Stewart-Cox, B., and R. Quinnell. 1990. Using calls, footprints and sightings to survey Green Peafowl in western Thailand. Pages 129-137 in D. A. Hill, P. T. Garson, and D. Jenkins, editors. Pheasants in Asia: China 1989. WPA, Reading, UK.

Sutherland, W. J., and R. E. Green. 2004. Habitat assessment. Pages 251-268 in W. J. Sutherland, I. Newton, and R. E. Green, editors. Bird ecology and conservation: a handbook of techniques. Oxford University Press, New York, New York, USA. http://dx. doi.org/10.1093/acprof:oso/9780198520863.003.0011

Wang, N., G. Zheng, and P. J. K. McGowan. 2012. Pheasants in sacred and other forests in western Sichuan: their cultural conservation. Chinese Birds 3:33-46. http://dx.doi.org/10.5122/ cbirds. 2012.0003

Wang, S., and Y. Xie. 2004. China species red list. Higher Education Press, Beijing, China.

Wen, L. Y., J. W. Gong, N. F. Liu, and P. Jing. 2008. Ecological habits of Tetraophasis szechenyii in Yajiang County, Sichuan Province. Sichuan Journal of Zoology 27:426-428. 
Wu, Y., J. Peng, and H. Gao. 1994. Study on breeding ecology of the Pheasant Grouse. Acta Ecologica Sinica 14:221-222.

Xu, J. L., X. H. Zhang, Z. W. Zhang, G. M. Zheng, X. F. Ruan, J. G. Zhu, and B. Xi. 2006. Multi-scale analysis on wintering habitat selection of Reeve's Pheasant (Syrmaticus reevesii) in Dongzhai National Nature Reserve, Henan Province, China. Acta Ecologica Sinica 26:2061-2067. http://dx.doi.org/10.1016/ S1872-2032(06)60031-0

Xu, Y., B. Wang, L. Dou, J. H. Ran, S. R. Liu, and B. J. Li. 2014. Roost selection by Buff-throated Partridge females with chicks during two weeks post hatch. Sichuan Journal of Zoology 33:641-645. http://dx.doi.org/10.3969/j.issn.1000-7083.2014.05.001

Xu, Y., N. Yang, B. Wang, L. Dou, H. Q. Yue, S. R. Liu, and J. H. Ran. 2016. Seasonal habitat use of a rare high-mountain Galliform species, the Buff-throated Partridge (Tetraophasis szechenyii). North-Western Journal of Zoology, in press.

Xu, Y., N. Yang, Y. Wang, B. S. Yue, and J. H. Ran. 2010. Roosting behavior and roost selection by Buff-throated Partridges Tetraophasis szechenyii during the breeding season. Zoological Studies 49:461-469.

Xu, Y., N. Yang, K. Zhang, B. S. Yue, and J. H. Ran. 2011. Cooperative breeding by Buff-throated Partridge Tetraophasis szechenyii: a case in the Galliformes. Journal of Ornithology 152:695-700. http://dx.doi.org/10.1007/s10336-011-0651-Z

Yang, N., T. C. Moermond, H. Lloyd, Y. Xu, L. Dou, K. Zhang, B. Yue, and J. Ran. 2016. Effects of supplementary feeding on the breeding ecology of the Buff-throated Partridge in a Tibetan sacred site, China. PLoS One 11:e0146568. http://dx.doi. org/10.1371/journal.pone.0146568

Yang, N., K. Zhang, H. Lloyd, J. Ran, Y. Xu, B. Du, B. Yue, Y. Wang, and S. Klaus. 2011. Group size does not influence territory size and overlap in a habituated population of a cooperative breeding Himalayan Galliforme species. Ardea 99:199-206. http:// dx.doi.org/10.5253/078.099.0210

Zhang, K., N. Yang, Y. Xu, J. Ran, H. Lloyd, and B. Yue. 2011. Nesting behavior of Szechenyi's Monal-partridge in treeline habitats, Pamuling Mountains, China. Wilson Journal of Ornithology 123:93-96. http://dx.doi.org/10.1676/10-035.1 